\title{
Quality of life in Chinese family caregivers for elderly people with chronic diseases
}

\author{
Hui Xie ${ }^{1,2}$, Cheng Cheng ${ }^{2}$, Yisheng Tao ${ }^{2}$, Jie Zhang ${ }^{3,4}$, Delprino Robert ${ }^{5}$, Jihui Jia ${ }^{1}$ and Yonggang Su ${ }^{6^{*}}$ (D)
}

\begin{abstract}
Background: Inadequate studies have been conducted in China to examine quality of life in family caregivers. Quality of life in family caregivers for elderly people with chronic diseases was evaluated, and the demographic and characteristic factors of both elderly people and their caregivers were explored.

Methods: The 36-Item Short Form Health Survey (SF-36) was used to assess health-related quality of life in 407 family caregivers caring for elderly people with chronic diseases in six communities on the Mainland China. The explanatory variables included family caregivers' demographic and other caregiving variables related to eldercare. Descriptive statistics and multiple linear regression analysis were used in the data analysis, performed via SPSS 17.0.

Results: Mean SF-36 and physical and mental component scores were 66.14 $\pm 17.50,70.06 \pm 16.49$, and 62.22 \pm 18 . 51 , respectively. The scores of caregivers' physical function and bodily pain were significantly higher, while the scores of caregivers' role limitations due to physical problems, general health, vitality, social function, mental health and role limitations due to emotional problems were significantly lower. Caregivers' ages, comorbidity, the perceived effects of caregiving on caregivers' social lives and elderly individuals' ages, marital status and Activities of Daily Living scores were significantly associated with the physical component score. In addition, caregivers' age, the affordability of the elderly person's healthcare expenses, the perceived effects of caregiving on caregivers' social lives, and elderly people's marital status and ADL scores were significantly associated with the mental component score.
\end{abstract}

Conclusion: Family caregivers for elderly people with chronic diseases showed poorer mental and better physical well-being. Factors of both elderly people and their caregivers impact the caregivers' quality of life. These findings highlight the importance of addressing mental health of family caregivers, and of providing economical support and psychological care for them.

Keywords: Family caregiver, Quality of life, Chronic diseases, Elderly, Activities of daily living

\section{Background}

Confronted with nation-wide aging problems and influenced by traditional culture, more and more Chinese people are undertaking the task of caring their aging parents or other elderly members. Currently, on the mainland China, approximately one fifth of the total population is aged 60 years and older, accounting more than 200 million in total. This segment of the population will increase to 400 million within 10 years [1]. Nearly $60 \%$ of elderly Chinese people are estimated to have

\footnotetext{
* Correspondence: syg@sdu.edu.cn

${ }^{6}$ School of Foreign Languages and Literature, Shandong University, Jinan 250012, Shandong, China

Full list of author information is available at the end of the article
}

experienced various chronic diseases [2]. The risk of disability in the elderly population increases with the development of chronic diseases, which often increases the demand for special care and support [3]. Due to profound influence of Confucian philosophy whose cultural norm holds that the elderly should be honored and respected and thus be cared in their own homes and by their family members, a considerable proportion of elderly Chinese people choose to receive support and care from family caregivers [1].

Family caregivers are family members who provide a minimum of $1 \mathrm{~h}$ of daily care for at least 3 months for care-recipients [4]. A spouse, child, relative, neighbor, or friend could be a caregiver. The potential gains for a 
caregiver can include positive factors such as selfsatisfaction, reciprocity, and the sense of duty having been fulfilled [2,3,5-7]. The activities involved in caring for a chronically ill person could also exert a negative impact on caregiver's health [8]. However, family caregivers' health status influences the quality of care for elderly people, similarly, providing home care for someone with a chronic disease can impact caregivers' physical and psychological health [9]. A cross-sectional study involving hemodialysis patients and their caregivers reported that one third of caregivers were moderately to severely depressed [10]. Gaskamp found that reduction in home health care was associated with decreased quality of life and increased depression among family caregivers of patients [11]. Another study found that caregivers were significantly more likely to display depressive symptoms and meet the diagnostic cutoff for depression relevant to non-caregivers (40\% for caregivers versus $5 \%$ for non-caregivers). Also, one quarter of the targeted caregivers reported taking antidepressant medication for depression [12]. Heesoo et al. found that the number of incremental and informal caregiving hours attributable to stroke among the elderly was 8.5 per patient per week [13]. In China, a study conducted in Beijing reported that the prevalence rate for depressive symptoms in elderly patients' family caregivers was $51.2 \%$ [14]. Peng conducted a qualitative study of family caregivers for disabled elderly people in Guangzhou, and showed that daily tasks as well as psychological and economic pressures affected caregivers' physical and mental health, work performance and quality of life [15].

Relative to evaluating the health status of family caregivers from a certain dimension, quality of life can be used to measure the comprehensive status of family caregivers. Quality of life (QoL) is a measurement of the quality of daily life including emotional, social, and physical factors [16]. QoL ratings have been found to be an appropriate metric for the design and implementation of service plans [17]. The International Working Group for the Harmonization of Dementia Guidelines has recommended that QoL be included as an outcome measure in all dementia trials [18].

Previous investigations focused mainly on burden $[19,20]$, psychological health [21], and QoL in family caregivers for elderly patients with dementia [22]. Literature review showed that few studies have been conducted to examine QoL of family caregivers in China and to the research on inpatients. In addition, most did not examine the impact of elderly care recipients to caregivers. Therefore, this study aimed to (1) examine QoL in family caregivers for elderly people with chronic diseases, using the 36-Item Short Form Health Survey (SF-36), and (2) explore the demographic and characteristic factors of both elderly people and their caregivers.

\section{Methods}

\section{Sampling}

A cross-sectional study was carried out with a convenience sample of 6 community health centers from 3 districts from Bengbu, an industrial city with a moderate economic level in Anhui Province in central China. Based on the official records, there are 335,869 residents aged 60 years and above in the city and the mean family income is about 2,197 RMB a month [23]. At the recruitment stage, an invitation letter which explained the purpose of the study was sent to each family, inviting the family caregiver to participate in the study. Family caregivers were eligible to participate if they were 18 years or older, provided home care for a family member older than 60 years of age (according to the standard definition of older persons in developing countries [24]) with one or more chronic diseases, able to communicate in Chinese, and provided home care for more than $5 \mathrm{~h}$ per week for more than 3 months [25].

Of the 726 eligible referrals, $38 \%$ refused to participate, primarily reporting lack of time or interest as major reasons. Thus, a total of 450 family caregivers were enrolled in this study. For the care recipients included in the study, $4.7 \%$ had cognition impairment, hearing loss or acute hospitalizations. The sample at the completion of data collection decreased from 450 to 429. Of those $5.1 \%$ were dropped from the sample due to invalid questionnaires they provided at one of the data collection points. The final sample used for analysis consisted of 407 family caregivers (see Fig. 1).

\section{Measurement Instruments Quality of life}

The primary outcome variable, Quality of Life (QoL), was measured using the 36-Item Short Form Health Survey (SF-36), which was designed to allow self-evaluation of quality of life and summarized the concept of health. It is an extensively applicable scale, and the Chinese version was developed by Ware [26]. The SF-36 consists of 36 questions and two summary scores: physical and mental component scores (PCS and MCS respectively). The PCS consists of the following dimensions: physical function (PF), role limitations due to physical problems (RP), bodily pain (BP), and general health (GH). The MCS consists of the following dimensions: vitality (VT), social function (SF), mental health $(\mathrm{MH})$, and role limitations due to emotional problems (RE) [27]. Individual item scores are summed up and transformed into a 0-100 scale ranging from the worst possible QoL to the best possible QoL [28]. Cronbach's $\alpha$ for the current sample was 0.88 .

\section{Demographic and health characteristics of caregivers and care recipients}

Caregivers' demographic and other characteristics included gender, age, marital status, educational level, occupation, 


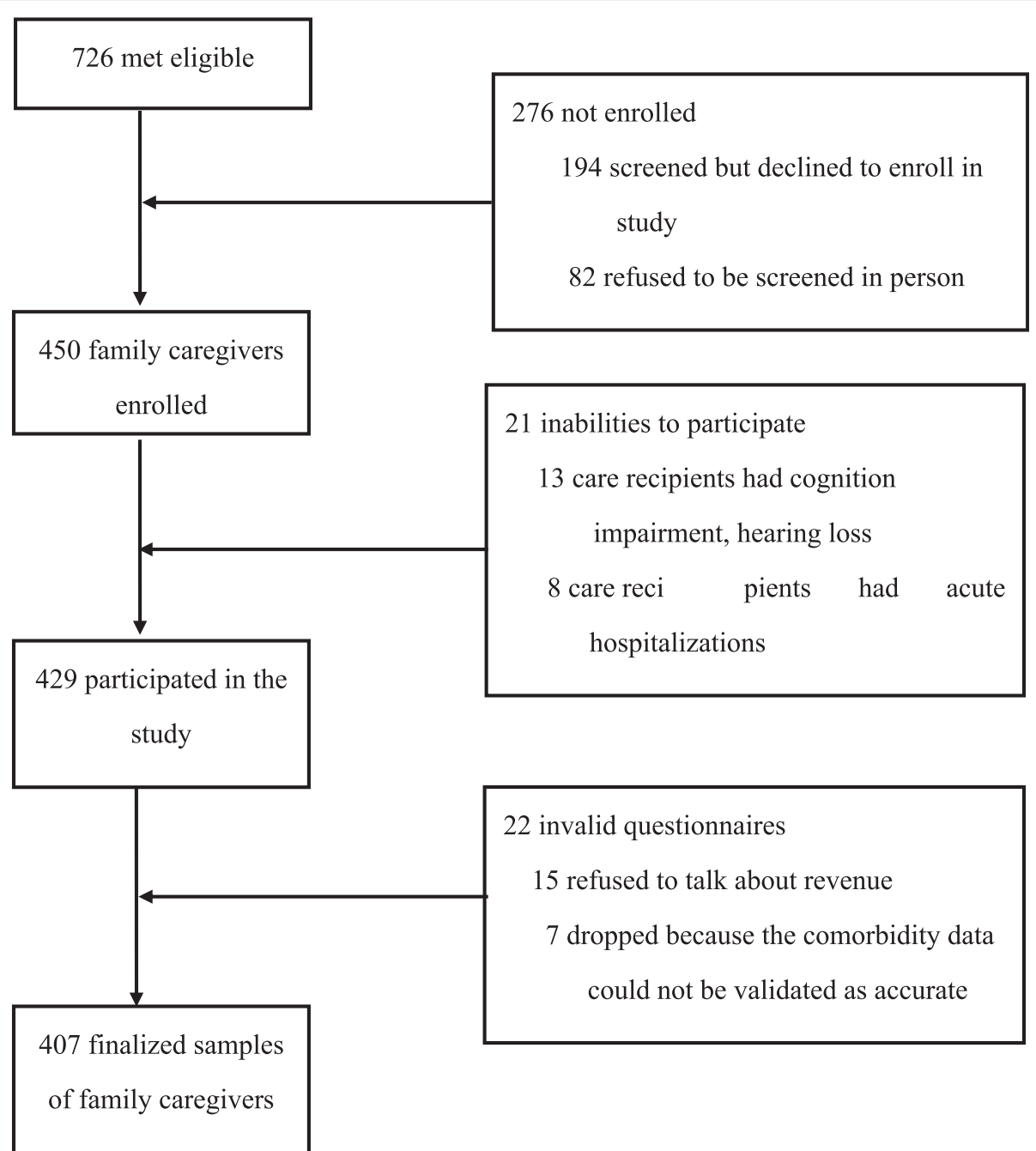

Fig. 1 Numbers of family caregivers who were screened, enrolled, and completed study

monthly revenue, and comorbidity. Explanatory variables for elderly people with chronic diseases included functional status and demographic characteristics including gender, age, marital status, educational level, healthcare insurance, and comorbidity. Care recipients' functional status was measured via the Activities of Daily Living (ADL) Scale, which includes Physical [29] and Instrumental Activities of Daily Living (ADL and IADL respectively) subscales [30]. The ADL subscale assesses 6 types of ability: bathing, dressing, using the toilet, transfer, eating, and others. The IADL subscale assesses the ability to perform 8 types of more complex activities, such as using the phone or transportation and going shopping. Scores for ability to perform activities range from 1 to 4 ( 1 point for each activity performed without help and 4 points for each activity that the individual is unable to perform). The maximum score is 56 (higher scores indicate greater dependence). Ramos validated the ADL scales in a Brazilian sample, demonstrating Cronbach's alpha of 0.88 [30]. Elderly people were classified into
3 categories according to degree of dependence: independent ( $<16$ points), partially dependent (16-22 points), and severely dependent (a total score of $>22$ or more than 2 items with scores of $\geq 3$ ) [31]. Cronbach's $\alpha$ for the current sample was 0.93 .

\section{Caregiving factors}

Caregiving factors examined in the study included the relationship to the elderly person (spouse, child, parent, or other), overall caregiving duration, average daily caregiving duration, affordability of the elderly person's healthcare expenses ( $\geq 90,89-50 \%, 49-11 \%, \leq 10 \%)$, and importance of the perceived effects of caregiving on the caregiver's social life (important, relatively important, slightly important, or not important at all).

\section{Procedure}

Approval was obtained from the 6 community health centers. Data were elicited primarily via in-person interviews 
with caregivers and care recipients conducted by bachelor's prepared research assistants with specialized preparation in the use of the questionnaires and data collection processes provided by the research team. The research assistants visited the participants' homes and explained the purpose of the study, seeking voluntary participation. Consent was obtained from the caregivers and care recipients who agreed to participate. The comorbidity data of caregivers and care recipients were obtained by research assistants from enrollees' medical records.

\section{Statistical analysis}

All questionnaire responses were recorded using Epidata 3.1 [32], and analyses were performed using SPSS version 17 (SPSS Inc., Chicago, IL, USA) statistical software. Caregivers' and elderly individuals' characteristics were expressed as frequencies or percentages for categorical variables and means with standard deviations for continuous variables. Overall SF-36 scores, the PCS and MCS, and scores for the 8 subscales of the SF-36 were calculated using scoring algorithms. A single-sample $t$ test was performed to estimate the differences between caregivers' scores and Chinese general population norms. Multivariate linear regression analyses were performed, using the PCS and MCS as separate dependent variables. Variables concerning several demographic and other characteristics for caregivers and the elderly were entered as independent variables.

\section{Results}

\section{Participant characteristics}

Table 1 shows the three main types of data collected, the first of which includes characteristics of both family caregivers and the elderly. Elderly care recipients' minimum and maximum ADL scores were 17 and 54, respectively. Their average ADL score was 21.05, with 294 and 113 elderly people classed as partially and severely dependent, respectively. The prevalence rate for hypertension in elderly people with chronic disease was $29.6 \%$, and coronary disease $9.9 \%$, diabetes mellitus $9.6 \%$, rheumatic arthritis $9.5 \%$, cerebrovascular disease $9.2 \%$ etc. (see Additional file 1) In addition, 379 (93.1 \%) elderly people had medical insurance, which included 123 (30.2 \%) urban resident basic medical insurance and 167 (41.0 \%) rural cooperative medical insurance.

\section{QoL in Participants and the General Population}

The results for the eight dimensions of the SF-36 are presented in Table 2. Mean values and standard deviation for the overall SF-36 score, PCS, and MCS were $70.06 \pm 16.49 ; 62.22 \pm 18.51$, and $66.14 \pm 17.50$, respectively. Caregivers' PF and BP were significantly higher relative to the Chinese national norms, which were calculated using 17,754 study subjects who were randomly selected from six cities of China [33]. In addition, caregivers' RP, GH, VT, SF, RE, and MH scores were significantly lower relative to those of the general population. The reduction in caregivers scores was approximately 25 points below the scores for RP and RE norms and approximately 10 points below that for $\mathrm{GH}$.

\section{Factors Significantly Associated with Family Caregivers' QoL}

After the explanatory variables associated with family caregivers' SF-36 scores had been considered, caregivers' age and comorbidity, recipients' age, marital status, and ADL scores, and the perceived effects of caregiving on caregivers' social lives were significantly associated with the PCS (Table 3). Of these 6 variables, caregivers' age explained the largest proportion of the variance in the PCS (PCS model: $F=9.428, P=0.000, R=0.577, R^{2}=0.333$, adjusted $R^{2}=$ $0.298, \mathrm{SE}=12.167)$. For the MCS scale, caregivers' age and comorbidity, care recipients' marital status and ADL scores, the affordability of the elderly person's healthcare expenses, and the perceived effects of caregiving on caregivers' social lives were significantly associated with the MCS. Of these variables, the perceived effects of caregiving on caregivers' social lives explained the largest proportion of the variance in the MCS (MCS model: $F=7.498, P=0.000, R=0.533$, $R^{2}=0.285$, adjusted $R^{2}=0.247$, and $\mathrm{SE}=11.080$ ).

\section{Discussion}

\section{Participants' QoL}

The present study examined QoL of caregivers for elderly people with chronic diseases, with subjective assessment of well-being and factors concerning both caregivers and the elderly. The findings of this study indicated that there was a substantial difference between caregivers and the general population; family caregivers displayed superior PF and fewer reports of BP relative to the general population. These findings are likely to have occurred because most caregivers (56.2\%) were aged 40-60 years, $50.8 \%$ were employed, and $65.1 \%$ did not have chronic diseases. In addition, superior physical functioning may have been one of the reasons why these caregivers cared for their elderly relatives [34]. Further, caregivers displayed lower values for the MCS. The burden and stress of fulfilling both family and work commitments were sufficiently severe to affect the psychological and social aspects of their personal quality of life, particularly with respect to RE, RP, and GH.

Another Asian study found that primary caregivers for elderly people with chronic diseases showed poorer mental and better physical well-being relative to population norms in Taiwan [35]. Relative to their results, scores for RE and RP in our study were $15-20$ points lower. A previous study suggested that a difference of 35 points was clinically meaningful [36]; therefore, this 
Table 1 Characteristics of Caregivers and Elderly People with Chronic Diseases, and Descriptive Statistics $(n=407)$

\begin{tabular}{|c|c|c|c|c|}
\hline & \\
\hline Characteristic & Caregiver & Elderly & other relatives & $17(4.1)$ \\
\hline & $n(\%)$ & $n(\%)$ & \multicolumn{2}{|l|}{ Overall caregiving duration (year) } \\
\hline Gender & & & $<1$ & $112(27.5)$ \\
\hline male & $175(43.0)$ & $168(41.3)$ & $1-2$ & $88(21.6)$ \\
\hline female & $232(57.0)$ & $239(58.7)$ & $3-5$ & $87(21.4)$ \\
\hline Age & & & $6-9$ & $48(11.8)$ \\
\hline $20-39$ & $65(16.0)$ & & $10+$ & $72(17.7)$ \\
\hline $40-59$ & $229(56.2)$ & & \multicolumn{2}{|l|}{ Average daily caregiving duration (hours) } \\
\hline $60-69$ & $113(27.8)$ & 153 (37.6) & $<2$ & $178(43.8)$ \\
\hline $70-79$ & & $192(47.2)$ & $2-3$ & $127(31.2)$ \\
\hline $80+$ & & $62(15.2)$ & $4-5$ & 71 (17.4) \\
\hline Marital status & & & $6+$ & $31(7.6)$ \\
\hline married & 381 (93.6) & $284(69.8)$ & \multirow{2}{*}{\multicolumn{2}{|c|}{$\begin{array}{l}\text { Affordability of the elderly person's } \\
\text { healthcare expenses }\end{array}$}} \\
\hline unmarried/widowed/separation & $26(6.4)$ & $123(30.2)$ & & \\
\hline Education level & & & $\geq 90 \%$ & $43(10.5)$ \\
\hline illiterate & $45(11.0)$ & $160(39.3)$ & $89 \%-50 \%$ & $183(45.0)$ \\
\hline elementary school & $67(16.5)$ & $125(30.7)$ & $49 \%-11 \%$ & $151(37.1)$ \\
\hline secondary school & $146(35.9)$ & $82(20.2)$ & $\leq 10 \%$ & $30(7.4)$ \\
\hline high school or professional training & $98(24.1)$ & $31(7.6)$ & \multirow{2}{*}{\multicolumn{2}{|c|}{$\begin{array}{l}\text { Importance of the perceived effects of } \\
\text { caregiving on the caregiver's social life }\end{array}$}} \\
\hline college and above & $51(12.5)$ & $9(2.2)$ & & \\
\hline Occupation & & & important & 55 (13.5) \\
\hline employed & $207(50.8)$ & & relatively important & $186(45.7)$ \\
\hline retired & $89(21.9)$ & $205(50.4)$ & slightly important & $147(36.1)$ \\
\hline never been employed or others & $111(27.3)$ & $202(49.6)$ & not important at all & $19(4.7)$ \\
\hline
\end{tabular}

Average monthly revenue (RMB)

$\begin{array}{ll}\leq 500 & 26(6.4) \\ 501-1000 & 78(19.2) \\ 1001-2000 & 114(28.0) \\ 2001-3000 & 104(25.5) \\ >3000 & 85(20.9)\end{array}$

Comorbidity (hypertension, coronary disease, diabetes mellitus, etc.)

$\begin{array}{ll}\text { none } & 265(65.1) \\ \text { one } & 103(25.3) \\ \text { two } & 23(5.7) \\ \text { three and more } & 16(3.9) \\ \text { Activities of Daily Living } & \\ \text { independent } & \\ \text { partially dependent } & \\ \text { severely dependent } & \\ \text { Relationship to the elderly person } & \\ \text { spouse } & 109(26.8) \\ \text { children } & 201(49.4) \\ \text { children in-law } & 80(19.7)\end{array}$

Table 1 Characteristics of Caregivers and Elderly People with Chronic Diseases, and Descriptive Statistics ( $n=407)$ (Continued)

discrepancy indicates that the family caregivers in the current study were a vulnerable group. With respect to caregiver characteristics, $57 \%$ were women, and $76.2 \%$ were spouses and children. These findings are consistent with results from other national studies involving caregivers for elderly people $[37,38]$. Also this reinforces the social and cultural roles attributed to women in terms of domestic activities and care for family members. If elderly people were unable to care for their spouses because 107 (26.3) of their own health problems, their children assumed re103 (25.3) sponsibility. Providing help with daily activities and fiprocess, in reciprocation for the care they received as children, and as an act of love and respect for their parents. Further, $93.6 \%$ of caregivers were married, similar to the findings of other related studies [5,39]. The cost $0(0.0)$ $294(72.2)$ $113(27.8)$ of accommodation and long-term care for the elderly could exert a negative impact on caregivers' health and the quality of care provided. Caregivers need help from the community, the government, and volunteers, to obtain spiritual and physical support, particularly with respect to medical treatment [34]. Emotional and social deprivation, which could result from 197 (48.4) nancial support was part of a natural and expected 
Table 2 Comparison of scores for the eight dimensions of the SF-36 between caregivers and the general population

\begin{tabular}{|c|c|c|c|c|}
\hline & \multirow{2}{*}{$\begin{array}{l}\text { Caregiver } \\
\text { Mean } \pm S D\end{array}$} & \multirow{2}{*}{$\begin{array}{l}\text { General population } \\
\text { Mean } \pm \text { SD }\end{array}$} & \multirow[t]{2}{*}{$t$} & \multirow[t]{2}{*}{$P$} \\
\hline & & & & \\
\hline Physical Function (PF) & $90.65 \pm 8.53$ & $87.92 \pm 16.98$ & 4.397 & $<0.001$ \\
\hline Role Physical (RP) & $52.64 \pm 34.39$ & $77.50 \pm 34.86$ & -14.581 & $<0.001$ \\
\hline Bodily Pain (BP) & $84.60 \pm 9.91$ & $82.22 \pm 16.98$ & 2.408 & 0.016 \\
\hline General Health $(\mathrm{GH})$ & $52.36 \pm 13.15$ & $62.51 \pm 17.88$ & -15.570 & $<0.001$ \\
\hline Vitality (VT) & $66.52 \pm 10.39$ & $68.17 \pm 17.63$ & -3.196 & 0.002 \\
\hline Social Function (SF) & $75.71 \pm 16.71$ & $80.67 \pm 19.98$ & -5.935 & $<0.001$ \\
\hline Role Emotional (RE) & $40.96 \pm 35.09$ & $67.86 \pm 39.44$ & -15.220 & $<0.001$ \\
\hline Mental Health $(\mathrm{MH})$ & $65.67 \pm 11.86$ & $68.47 \pm 16.90$ & -4.762 & $<0.001$ \\
\hline
\end{tabular}

ingrained cultural values and norms, is more difficult to identify and address $[40,41]$.

\section{Significant Factors Associated with Family Caregivers'}

QoL

The impact of elderly individuals' characteristics

The age of elderly individuals was the main influential factor in the PCS. This is consistent with findings from previous studies $[42,43]$. Age was considered the most crucial factor studied (See Table 3). The age of elderly individuals was noted as an important factor in assessing caregivers' health status.

Elderly individuals' marital status and ADL scores were also influential for family caregivers in both the PCS and MCS. The elderly people's higher dependence was associated with greater burden for caregivers [5]. As

Table 3 Multivariate models of factors concerning caregivers and the elderly for the PCS and MCS in caregivers for the elderly $(n=407)$

\begin{tabular}{|c|c|c|c|c|}
\hline \multirow[t]{2}{*}{ variables } & \multicolumn{4}{|l|}{ PCS MCS } \\
\hline & $\beta(\mathrm{SE})$ & $\beta^{a}$ & $\beta$ (SE) & $\beta^{a}$ \\
\hline \multicolumn{5}{|l|}{ Caregivers' demographic factors } \\
\hline age & $-0.389(0.073)$ & $-0.337^{*}$ & $-0.201(0.069)$ & $-0.198^{*}$ \\
\hline gender & $-0.308(1.243)$ & -0.011 & $-1.099(1.175)$ & -0.043 \\
\hline marital status & $2.766(2.091)$ & 0.056 & $2.328(1.976)$ & 0.053 \\
\hline education level & $-0.493(0.618)$ & -0.042 & $-0.392(0.584)$ & -0.038 \\
\hline occupation & $-0.030(0.417)$ & -0.003 & $0.067(0.394)$ & 0.008 \\
\hline average monthly revenue & $0.746(0.569)$ & 0.061 & $0.220(0.538)$ & 0.020 \\
\hline comorbidity & $-5.630(0.874)$ & $-0.301^{*}$ & $-2.833(0.826)$ & $-0.172^{*}$ \\
\hline \multicolumn{5}{|l|}{ Elderly' demographic factors } \\
\hline age & $-0.217(0.108)$ & $-0.102^{*}$ & $-0.083(0.102)$ & -0.044 \\
\hline gender & $1.538(1.321)$ & 0.053 & $0.654(1.248)$ & 0.025 \\
\hline marital status & $-1.639(0.725)$ & $-0.103^{*}$ & $-1.774(0.685)$ & $-0.126^{*}$ \\
\hline education level & $-0.291(0.624)$ & -0.022 & $-0.575(0.589)$ & -0.049 \\
\hline$A D L$ & $-0.203(0.096)$ & $-0.107^{*}$ & $-0.327(0.091)$ & $-0.195^{*}$ \\
\hline \multicolumn{5}{|l|}{ Caregiving factors } \\
\hline relationship to the elderly person & $-0.173(0.706)$ & -0.015 & $-0.930(0.667)$ & -0.091 \\
\hline overall caregiving duration & $0.391(0.454)$ & 0.038 & $0.027(0.429)$ & 0.003 \\
\hline average daily caregiving duration & $1.049(0.772)$ & 0.068 & $0.958(0.729)$ & 0.071 \\
\hline $\begin{array}{l}\text { affordability of the elderly person's } \\
\text { healthcare expenses }\end{array}$ & $1.567(0.861)$ & 0.083 & $2.490(0.813)$ & $0.150^{*}$ \\
\hline $\begin{array}{l}\text { importance of the perceived effects of } \\
\text { caregiving on the caregiver's social life }\end{array}$ & $5.185(0.915)$ & $0.274^{*}$ & $4.681(0.865)$ & $0.282^{*}$ \\
\hline
\end{tabular}

$\beta$ represents estimated regression coefficient, standing for the mean difference between the index and reference categories and standing for the average increase (decrease) in 2 scales of the SF-36 for each 1-unit increase for continuous variables; SE represents standard error

a Standardized regression coefficient; ${ }^{*} P<0.05$ 
care recipients demanded more help, the average burden of daily caregiving increased. This exerted a greater impact on caregivers' lives and work, and increased their pressure, leading to the deterioration of their own health. Older, married elderly people received greater social support and shared the burden and pressure with caregivers $[39,44]$, which reduced the impact exerted on the caregivers' physical and mental health.

Elderly individuals' comorbidities were not influential factor for family caregivers in both the PCS and MCS, which was inconsistent with the results of Dauphinot who stated that the caregiver's burden was higher when patients' comorbidities increase [45]. This related to the fact that most elderly individuals were partially dependent $(72.2 \%)$ and were suffering with more than two kinds of comorbidities (73.7 \%), which need to expand the sample and analyze the data via the classification of comorbidity.

\section{The impact of caregivers' characteristics}

The results showed that caregivers' older age and additional comorbidities were risk factors with respect to the PCS and MCS; this was consistent with results of previous studies $[42,43]$ and may be related to normal human growth and development. Young people tend to be more physically vigorous and better functioning physiologically, with less complaint for bodily pain and more energy for social activities, which provides temporary relief from the family caregiver role [43]. In addition, this energy enables people to function socially, reducing the occurrence of psychological problems, such as anxiety and depression, and contributing to the good maintenance of mental health. With increasing age, strength wanes and function of the human body deteriorate, increasing the risk of illness. Family caregivers with chronic diseases were required to endure the pain caused by their own diseases in addition to taking care of their elderly family members. This led to deterioration in their health and evoked anxiety, depression, and other negative emotions [46,47]. This phenomenon occurs more frequently in senior family caregivers. Age exerted the most direct impact on caregivers' health; therefore, adequate attention should be paid to senior caregivers, who should be provided with appropriate assistance.

\section{The impact of accommodation}

Although $93.1 \%$ of elderly in this study had a pension and pension insurance, the pension was for the payment of medical expenses for inpatient care and not for the long term care. So, $82.1 \%$ of caregivers were required to use their own incomes to cover part of the costs of caring for elderly family members. Use of one's own financial resources to care for an elderly person interferes with the family economy and dynamics, which could create stress and financial burden. Previous studies have shown that family caregivers' psychological burden was significantly affected by economic pressure and led to anxiety, depression, and other psychological problems in the long term [20]. China has a growing elderly population, which requires comprehensive official arrangements for the provision of basic guarantees and services. According to the results of the study, the cost of accommodation for the elderly could affect family caregivers psychologically. The lack of assistance and economic support available for the elderly has revealed that social security and assistance services do not function successfully. In addition, governments at all levels should provide economic and administrative maintenance for this care sector, particularly for long-term care.

\section{The perceived effects of caregiving on caregivers' social lives}

The perceived effects of caregiving on caregivers' social lives constituted an important factor with respect to the MCS. The impact that care activities exert on family caregivers affects their health. Prolonged care activities impact quality of life including distress over managing complex care, disrupted social activities, depression and fatigue, withdrawal from family or friends and even lost of employment [48]. On account of a lack of pension institutions and supports, community care is currently in its infancy in China. In addition, with the impact of traditional Chinese culture, family caregivers assume major responsibility for taking care of family members. This increases economic pressure and ultimately affects family caregivers' health. In view of these issues, caregivers should be offered services providing physical, psychological, social, and economic supports. For example, a health records information system should be established for family caregivers. Community health professionals could provide health education sessions and organize special events for family caregivers. This would increase interaction between family caregivers and allow them to establish social networks.

This study has two important implications for healthcare providers. First, positive psychological interventions and social support systems should be established to improve mental health of family caregivers. Second, governments should assume responsibility for implementing existing public policies and for extending those that target the prevention of health-related complications to promote caregivers' health, such as financial support and establishment of facilities, especially for those who are older, have higher rates of comorbidities, are economically burdened by the elderly person's healthcare expenses, and take care of unmarried, severely dependent elderly family members.

\section{Limitations}

The study was subject to some limitations. A crosssectional design was used; the current findings could be 
strengthened and a more accurate picture could be provided in future studies with a longitudinal design. In addition, the research involved only six communities within a single province of China. Although there were no differences between those who consented and those who declined in age and gender, the generalizability of the results is limited.

\section{Conclusion}

Family caregivers for elderly people with chronic diseases exhibited superior PF and poorer values for the MCS, particularly with respect to RE, RP, and GH, compared with Chinese population norms. Caregiving factors and the demographic characteristics of both caregivers and the elderly contributed to caregivers' QoL. Younger age and fewer comorbidities in caregivers as well as younger age, being married, and independent ADL status in the elderly were significantly associated with a higher PCS. Also, little importance to the perceived effects of caregiving on caregivers' social lives was significantly associated with a higher PCS. Older age and a higher number of comorbidities in caregivers in addition to severely dependent ADL status and being unmarried in the elderly, were significantly associated with a lower MCS. Greater importance to the perceived effects of caregiving on caregivers' social lives and capability to afford the majority of the elderly person's healthcare expenses, were also significantly associated with a lower MCS.

These findings highlight the importance of addressing mental health and of providing financial support and social well-being for family caregivers. Furthermore, greater attention should be given to the health of caregivers who are advanced in age, burdened by higher rates of comorbidities, shouldering the elderly person's healthcare expenses, or caring unmarried or severely dependent elderly family members. Governments at all levels should assume responsibility for implementing existing public policies, particularly with respect to the provision of financial support and establishment of facilities.

\section{Additional file}

Additional file 1: Table S1. Comorbidities of Caregivers and Elderly People with Chronic Diseases. (DOC 30 kb)

\footnotetext{
Abbreviations

$A D L$, activities of daily living; $B P$, bodily pain; $G H$, general health; IADL, instrumental activities of daily living; MCS, mental component scores; $\mathrm{MH}$, mental health; PCS, physical component scores; PF, physical function; QoL, quality of life; RE, role limitations due to emotional problems; RP, role limitations due to physical problems; SF, social function; SF-36, 36-item short form health survey; VT, vitality
}

\section{Acknowledgements}

This study was funded by the Ministry of Education of China Grant: (14YJAZH068) and Anhui Province Education Department Grant: (SK2014A310).
Thanks to Dr. Wang KF, Dr. Fan XZ and Dr. Feng DJ for their support and guidance during the research process. Also thanks to Dr. Li P and Chen XQ for the feedback on early written products from this research. Finally, many thanks to the peer reviewers at Health and Quality of Life Outcomes for providing constructive and insightful feedback to improve this manuscript.

\section{Authors' contributions}

Study concept and design the experiments: HX, JJ, DR, YS. Acquisition of data: CC, YT, HX. Analysis and interpretation of data: HX, JZ, JJ, YS. Drafting of the manuscript: HX, JJ, YS. Critical revision of the manuscript for important intellectual content: YS, JJ, JZ, DR, HX. Final approval of the version to be published: DR, JZ, HX, YS, JJ. All authors read and approved the final manuscript.

\section{Competing interests}

We declare we have no competing interests.

\section{Ethics approval and consent to participate}

The ethics committee of Bengbu Medical College approved the study (No. 2014-025) and granted permission to conduct the study. Participants read and signed informed consent agreements prior to the initiation of the study.

\section{Author details}

${ }^{1}$ School of Nursing, Shandong University, Jinan 250012, Shandong, China. ${ }^{2}$ Nursing Department, Bengbu Medical College, Bengbu 233030, Anhui, China. ${ }^{3}$ School of Public Health, Shandong University, Jinan 250012,

Shandong, China. ${ }^{4}$ Department of Sociology, State University of New York Buffalo State, Buffalo, NY, USA. ${ }^{5}$ Department of Psychology, State University of New York Buffalo State, Buffalo, NY, USA. ${ }^{6}$ School of Foreign Languages and Literature, Shandong University, Jinan 250012, Shandong, China.

Received: 5 December 2015 Accepted: 1 July 2016

Published online: 06 July 2016

\section{References}

1. Lu PP, Li HY. Study on the differences of the caring demands and abilities of the elderly in different caring modes. Chinese Gen Pract. 2015;18(15): $1780-5$

2. Liu Y, Guo GF. Aged care demand situation in our country and the thinking of aged care personnel training. Chinese Nursing Manag. 2011;11(4):5-9.

3. Liao CC, Li CR, Lee SH, Liao WC. Social support and mortality among the aged people with major diseases or ADL disabilities in Taiwan: A national study. Arch Gerontol Geriatr. 2015;60(2):317-21.

4. Okamoto K, Harasawa Y. Emotional support from family members and subjective health in caregivers of the frail elderly at home in Japan. Arch Gerontol Geriatr. 2009:49:138-41.

5. Fuhrmann AC, Bierhals CCBK. Santos, NO, Paskulin LMG: Association between the functional capacity of dependant elderly people and the burden of family caregivers. Rev Gaucha Enferm. 2015;36:14-20.

6. Shankar KN, Hirschman KB, Hanlon AL, Naylor MD. Burden Among Caregivers of Elders Who Were Cognitively Impaired at the Time of Hospitalization: A Cross-Sectional Analysis. J Am Geriatr Soc. 2014;62(2):276-84.

7. Chen HM, Huang MF, Yeh YC, Huang WH, Chen CS. Effectiveness of coping strategies intervention on caregiver burden among caregivers of elderly patients with dementia. Psychogeriatrics. 2015;5:20-5.

8. Huisman-de Waal G, Schoonhoven L, Jansen J, Wanten G, van Achterberg T. The impact of home parenteral nutrition on daily life-a review. Clin Nutr. 2007;26(3):275-88

9. Schulz R, Sherwood PR. Physical and Mental Health Effects of Family Caregiving. Am J Nurs. 2008;108(9):23-7.

10. Saeed Z, Ahmad AM, Shakoor A. Depression in patients on hemodialysis and their caregivers. Saudi J Kidney.

11. Gaskamp CD. Quality of life and changes in health insurance in long-term home care. Nurs Econ. 2004:22:107-46.

12. Mausbach BT, Chattillion EA, Roepke SK, Patterson TL, Grant I. A comparison of psychosocial outcomes in elderly Alzheimer caregivers and noncaregivers. Am J Geriatr Psychiatry. 2013;21:5-13.

13. Joo H, Dunet DO, Fang J, Wang G. Cost of Informal Caregiving Associated with Stroke among Elderly in the United States. Neurology. 2014;83(20):1831-7. 
14. Du J, Qian CG, Xu W, Shao S, Zhao YL, Wang HL. Depressive symptoms in family caregivers of disabled elderly in Beijing urban. Chinese Mental Health J. 2014;28(7):506-10

15. Peng ZQ. Research on social support of the caregiver for the disable elderly. Tianjin Normal university; 2010

16. Health-Related Quality of Life (HRQoL). Available at: http://www.cdc.gov/hrqol/

17. Degenholtz HB, Rosen J, Castle N, Mittal V, Liu D. The association between changes in health status and nursing home resident quality of life. Gerontologist. 2008;48:584-92.

18. Mack JL, Whitehouse PJ. Quality of Life in Dementia: State of the Art - Report of the International Working Group for Harmonization of Dementia Drug Guidelines and the Alzheimer's Society Satellite Meeting. Alzheimer Dis Assoc Disord. 2001: 69-71

19. Li H, Wang MD, Huang HL, Zhao HF. Analysis of family burden of family caregivers of elderly with chronic disease. Chinese J Nurs. 2009;44(6):561-4.

20. LV Q, Xu SQ, Sun YQ, Chen SM. Study on related factors of psychological burden of family caregivers of rural elderly patients with chronic disease. Chinese Nurs Res. 2013;27(8):2455-7.

21. Lu QF. The needs of support service for family caregivers of seniors. J Tongji University. 2012;33(3):109-16

22. Guo AM, Deng SH. Research Progress in the Quality of Life and Affecting Factors of Dementia Patients' Caregivers. J Dali University. 2010;9(12):49-52.

23. Profile of Bengbu. Available at:http://www.bengbu.gov.cn/english/. 2015.

24. Gu DN. Thinking about the age of the old people and the redefinition. Chinese J Popul Sci. 2000:3:42-52.

25. Zeng L, Zhou LS. A study on the content of social support services for the elderly's caregivers at home. Chinese Nurs Manag. 2012;12(11):22-5.

26. Zhang ZJ. Behavioral medicine inventory manual. Beijing: Chinese Medical Multimedia Press Co, LTD; 2005.

27. JE, Ware. SF-36 Health Survey: Manual and Interpretation Guide: The Health institute; 1993

28. JE W. SF-36 Physical and Mental Health Summary Scales: A User's Manual. Boston: Health Assessment Lab: New England Medical Center; 1994.

29. Katz S, Akpom CA. Index of ADL. Med Care. 1976;14(5):116-8.

30. Edwards MM. The reliability and validity of self-report Activities of Daily Living scales. Can J Occup Ther. 1990;57(5):273-8.

31. Wang XD, Wang XL, Ma H. Rating scales for mental health. Beijing Chinese Mental Health J. 1999;287.

32. Lauritsen JM. EpiData Data Entry, Data Management and basic Statistical Analysis System. Odense: EpiData Association. Retried from; 2000.

33. Pan TF, Si CZ, He HJ, Wang B, Shan GL. Survey of health-related quality of life in population of 6 Chinese cities. Basic Clin Med. 2011;31(6):636-41.

34. Jiang $\mathrm{FH}$. The care burden of the elderly spouse caregiver and the welfare policy. Nanjing Normal University; 2013

35. Li TC, Lee YD, Lin CC, Amidon RL. Quality of life of primary caregivers of elderly with cerebrovascular disease or diabetes hospitalized for acute care: Assessment of well-being and functioning using the SF-36 Health Questionnaire. Qual Life Res. 2004;13:1081-8.

36. Ware JE, Sherboume CD. The MOS 36-item short-form health survey (SF-36): conceptual framework and item selection. Med Care. 1992;30(6):473-83.

37. Benjamin J, Robbert H, Ruben DMK, Isabelle NF. The effects of an integrated care intervention for the frail elderly on informal caregivers: a quasiexperimental study. BMC Geriatr. 2014;14:58.

38. Yurtserver S, Özge A, Kara A, Yandim A, Kalav S, Yesil P. The relationship between care burden and social support in Turkish alzheimer patients family caregivers: cross-sectional study. J Nurs Educ Pract. 2013;3(9):1-12.

39. Pereira RA, Santos EB, Fhon JRS, Marques S, Rodrigues RAP. Sobrecarga dos cuidadores de idosos com acidente vascular cerebral. Rev Esc Enferm USP. 2013:47(1):185-92

40. Chen L, Ren $X H$, Huang LZ, Jiao J. Influencing factors of quality of life of primary caregivers of lung cancer patients undergoing chemotherapy. J Nurs. 2013;20(4B):1-4.

41. Du J, Qian CG, Xu W, Shao S, Zhao YL, Wang HL. Investigation of depressive mood in the family caregiver of the elderly in Beijing. Chinese J Mental Health. 2014;28(7):506-11.

42. Clay OJ, Grant JS, Wadley VG, Perkins MM, Haley WE, Roth DL. Correlates of health-related quality of life in African American and Caucasian stroke caregivers. Rehabil Psychol. 2013;58(1):28-35.

43. Morley D, Dummett S, Peters M, Kelly L, Hewitson P, Dawson J, Fitzpatrick R, Jenkinson C. Factors influencing quality of life in caregivers of people with
Parkinson's disease and implications for clinical guidelines. Parkinsons Dis. 2012:2012:190901.

44. Morais HCC, Soares AMG, Oliveira ARS, Carvalho CML, Silva MJ, Araujo TL. Burden and modifications in life from the perspective of caregivers for patients after stroke. Rev Latino-Am Enfermagem. 2012;20(5):944-53.

45. Dauphinot V, Ravier A, Novais T, et al. Relationship Between Comorbidities in patients with Cognitive Complaint and Caregiver Burden: A CrossSectional Study. J Am Med Dir Assoc. 2016;17(3):232-7.

46. Zou J. Study on the present situation and influential factors of care burden of family caregivers for patients with dementia. Hunan: Zhongnan University; 2014.

47. Jiang F. Study on care burden and positive experience and their influentia factors of caregivers of people with senile dementia in Changsha. Hunan: Zhongnan University; 2012

48. Smith CE, Piamjariyakul U, Yadrich DM, Ross VM, Gajewski B, Williams AR Complex home care: part III-economic impact on family caregiver quality of life and patients' clinical outcomes. Nurs Econ. 2010;28(6):393-414.

\section{Submit your next manuscript to BioMed Central and we will help you at every step:}

- We accept pre-submission inquiries

- Our selector tool helps you to find the most relevant journal

- We provide round the clock customer support

- Convenient online submission

- Thorough peer review

- Inclusion in PubMed and all major indexing services

- Maximum visibility for your research

Submit your manuscript at www.biomedcentral.com/submit
) Biomed Central 